International Journal of Environment, Agriculture and Biotechnology
Vol-6, Issue-5; Sep-Oct, 2021
JJEAB
Journal Home Page Available: https://ijeab.com/
Journal DOI: $10.22161 /$ ijeab

\title{
Willingness to pay for Pesticide-Safe Vegetables in Nepal
}

\author{
Januka Pandit ${ }^{1}$, Punya Prasad Regmi ${ }^{2}$, Gopal Bahadur K.C. ${ }^{3}$, Bikash Paudel ${ }^{4}$, Devendra \\ Gauchan $^{5}$
}

\author{
${ }^{1}$ M.Sc., Institute of Agriculture and Animal Science, Tribhuvan University, Nepal \\ ${ }^{2} \mathrm{Ph} . \mathrm{D}$., Agriculture and Forestry University, Nepal \\ ${ }^{3} \mathrm{Ph} . \mathrm{D}$., Institute of Agriculture and Animal Science, Tribhuvan University, Nepal \\ ${ }^{4}$ Ph.D., Nepal \\ ${ }^{5} \mathrm{Ph} . \mathrm{D}$., Alliance of Bioversity International and CIAT, Nepal \\ Corresponding author: Januka Pandit; email: januaec@gmail.com
}

Received: 21 Sep 2021; Received in revised form: 16 Oct 2021; Accepted: 23 Oct 2021; Available online: 31 Oct 2021

(C)2021 The Author(s). Published by Infogain Publication. This is an open access article under the CC BY license

(https://creativecommons.org/licenses/by/4.0/).

\begin{abstract}
Demand for pesticide-safe vegetables in affordable price is increasing because of consumers consciousness for their health. The objective of this study was to assess the consumers' willingness to pay for pesticide-safe vegetables in Nepal. A sample of 720 respondents, surveyed at four major markets in Nepal, analysed by Choice Base Conjoint method. The result showed that price was prioritized in majority of consumers in Pokhara, Chitwan and Butwal; and production method was prioritized in majority of consumers in Kathmandu. There was significantly negative preference to price in all markets and in all consumer segments. Almost all consumer segments in all markets had significantly positive preference for labelled products. Products produced under conventional systems were disliked by consumers, irrespective of market. Majority of consumers were willing to pay for switching to higher quality food-safety levels from low quality food safety levels. Therefore, the study concludes that there is a strong potential for establishing spacility market for pesticide-safe vegetables in Nepal.
\end{abstract}

Keywords-WTP; Choice Base Conjoint; Pesticide-free, Traditional and Organic vegetables; Labelling.

\section{INTRODUCTION}

There is increasing trend of demand for various types of pesticide-free/pesticide-safe agricultural and food products in recent decade (Aswathy \& Thomas, 2019; Edenbrandt, 2018) amid increased consumer awareness on health, environmental safety, harmful impact of pesticides and may be the impact of various 'buy local' movements (Ndlovu et al., 2016). Reciprocating to the changes in consumer preference, various production typologies such as - organic farming, agro-ecological farming, low input agriculture, good agriculture practice (GAP), biological farming, permaculture - have been proposed as technological solution to produce pesticide-safe agricultural commodities. There is also an increased attention to revive the traditional farming system due to various environmental and economic benefits (Singh and Singh, 2017). All these global patterns about change of consumer preference and search for alternative production methods are pertinent for Nepal.

The traditional farming system, which is still present in high hills and mountains, tends to be organic or chemicalfree by default due to century long production methods (Gauchan et al., 2020; Bhatta and Doppler, 2011). However, the pesticide use is growing very sharply in the country. Pesticide use of Nepal is $0.35 \mathrm{~kg} / \mathrm{ha}$, which is only $13 \%$ of worlds average of $2.69 \mathrm{~kg} / \mathrm{ha}$ (FAOSTAT, 2021). Rapidly growing commercial and semi-commercial fresh vegetable enterprises use highest amount of pesticides and have also stirred discussion about pesticide residue among urban consumers. There is increased media attention on pesticide residue on fresh vegetables which often puts vegetable growing farmers as culprit. Due to this, there is strong push for growers to adopt alternative production methods, like GAP, organic agriculture, integrated pest 
management (IPM), or return to traditional agriculture practices for supporting food safety issues.

Insects and pests cause about 35 percent crop loss in Nepal which compels application of insecticides and pesticides for crop protection (PQPMC, 2019). In addition, the current agricultural markets do not have any structure to differentiate different levels of pesticide-safe products to reap incentive for farmers to adopt alternative production methods. There are few organic outlets in few cities who claim to sell organic products but not only they are excessively expensive but their authenticity, product quality and traceability are uncertain (Singh \& Maharjan, 2015). Therefore, pesticide toxicity has been mentioned as a classic case of market failure since neither the negative externality of the pesticide is accounted nor the positive externalities of alternative methods are appreciated (Becker, 2017).

Market is an important pull factor for promotion of alternative production technologies. No effort for promotion of pesticide-safe vegetables would be sustainable without building incentive mechanisms within the market system. In Nepal, the demand for organic vegetables (and food products in general) is rapidly growing. Studies have also indicated that the healthconscious consumers in urban areas are interested to pay premium price for organic or pesticide-free vegetables (Khanal, 2020; Bhatta et al., 2010). It is also evident in few specialized organic market outlets who have been running the speciality market charging premium price to consumers.

One general limitation of this system is that this system gives consumers only binary choice from two ends of spectrum. Consumers can choose highly expensive organic products from specialty market or pesticide-laden products from conventional markets. There are relatively safer, midway alternatives such as: pesticide-free (not organic product because farmers may use chemical fertilizer, which is possible under pest control through IPM or GAP systems), traditional products (which are similar to organic product without organic certification), none of these midway alternatives are made available for consumers to choose. Very little is understood about how consumers perceive about these mid-way safer-than-conventional and cheaper-than-organic products which could provide a balanced compromise for food safety and affordability to urban consumers. Understanding consumer attitudes towards and preferences for these production methods, as well as determining consumers' willingness to pay (WTP) to these alternatives would, therefore, be of immense value to producers, marketers, and policy makers in the country.
In this context, this study was conducted to understand the market segmentation and consumers' WTP for different types of pesticide-safe vegetables produced under pesticide-free condition, traditional system and pure organic system in markets of Nepal. The specific objectives of this study were to: 1) assess consumers' preference for different attributes of pesticide-safe vegetables for different segments of market in Nepal by using choice-based conjoint technique, 2) quantify consumers' WTP for switching from conventional to pesticide-free, traditional, and organic farming products.

\section{MATERIALS AND METHODS}

\section{Study Area}

The primary data were collected through consumer survey in December 2019 from vegetable markets of four biggest urban centres of Nepal, i.e. - Kathmandu (Kalimati), Chitwan (Bharatpur), Butwal and Pokhara, through structured questionarrie.

\section{Sampling}

A systematic random sampling technique was applied at each market centre. Sampling was done among the consumers present at the vegetable market gates at the peak time of vegetable purchase. Systematically, every $4^{\text {th }}$ consumer passing from the gate was interviewed to observe the randomness in the sampling. If any sampled respondent did not answer, next person coming out from market gate was interviewed.

All together 720 consumers were surveyed for this study which accounted 180 from each market. The sample size of 180 was decided because this size was enough to ensure the validity of the Choice Base Conjoint (CBC) design with the intended levels of attributes.

The vegetables such as tomato, potato, cauliflower, and radish were considered for the study as these are most common vegetables traded in Nepalese market. However, very little or no difference was observed in respondents' responses by type of vegetable. Therefore, only tomato was retained for final survey as it has highest share in market transection and is available in all these market in all seasons.

\section{Analytical methods}

CBC model was chosen because it can analyse the data having large number of attributes of a good and it involves one attribute in monitory cost, and WTP can be calculated on estimated preference. It is possible to construct the preference over all attributes of each consumer.

For objective 1, to assess consumers' preference for different attributes of pesticide-safe vegetable for different 
consumer segments, CBC analysis was conducted. CBC was developed since 1960 for stated preference studies. The strategy of this method involves making inferences about the Part Worth of attribute levels from respondents stated choices (Raghavarao et al., 2010). Surveys asks respondents to make choice among alternatives based on levels of their attributes. Each attribute consists of different levels which is associated with different prices. Thus, CBC survey asks respondents to indicate their preferences for combinations of different levels of two or more attributes. The attributes and their levels for the $\mathrm{CBC}$ questionnaire with consumers for this study were as follows (Table 1):

Table 1: Attributes and levels for CBC analysis

\begin{tabular}{|c|c|c|}
\hline Attributes & Levels & \\
\hline \multirow[t]{4}{*}{ 1. Production methods } & 1.1) & $\begin{array}{l}\text { Conventional (use of both pesticide and chemical } \\
\text { fertilizer) }\end{array}$ \\
\hline & $1.2)$ & $\begin{array}{l}\text { Pesticide-free (no use of pesticide but may have } \\
\text { used chemical fertilizer) }\end{array}$ \\
\hline & 1.3) & $\begin{array}{l}\text { Traditional (no use of pesticide and no use of } \\
\text { chemical fertilizer) }\end{array}$ \\
\hline & 1.4) & $\begin{array}{l}\text { Organic (not allowed to pesticide use, not allowed } \\
\text { to chemical fertilizer use) }\end{array}$ \\
\hline \multirow[t]{2}{*}{ 2. Labelling/certification } & $2.1)$ & Without labelling/certification \\
\hline & 2.2) & With labelling/certification \\
\hline \multirow[t]{4}{*}{ 3. Price } & $3.1)$ & Regular market price \\
\hline & 3.2) & Maximum $15 \%$ higher than market price \\
\hline & 3.3) & Maximum $30 \%$ higher than market price \\
\hline & 3.4) & Maximum $45 \%$ higher than market price \\
\hline
\end{tabular}

The first attribute was vegetable production method, particularly related to how the insect/pest control has been done in field. This attribute had four levels starting from conventional (which uses pesticide-based pest control), pesticide-free (where pesticide use is not allowed but use of chemical fertilizers permitted), traditional production systems (no use of chemical fertilizer and no use of pesticide) and organic farming system (where both pesticide and chemical fertilizers are not permitted). Different levels of the first attribute provided the alternative, mid-way safer vegetable production methods which the study intended to assess WTP by consumers. The second attribute was labelling/certification which had binary levels - without or with labelling. Third attribute was price which was specified with four levels of premium price for greater levels of earlier two attribute combinations, i.e. no premium, $15 \%$ premium, $30 \%$ premium and $45 \%$ premium. Different levels of premium price were determined through focus group discussion and verified in pre-testing.

The questionnaire for the WTP was framed as the CBC. Ten different versions of the CBC questionnaire were generated by Sawtooth Software by randomizing the combinations of the choice options. Each version had 12 different choice sets where each choice set had 3 different combinations of different levels of the attributes.

Example question for CBC for latent class analysis

\begin{tabular}{|l|l|l|l|}
\hline Attributes & Option 1 & Option 21 & Option 36 \\
\hline Pest control methods & $\begin{array}{l}\text { Existing } \\
\text { method }\end{array}$ & Traditional & Organic \\
\hline Labeling & No labeling & No labeling & Labeling \\
\hline Price & Market price & $\begin{array}{l}\text { Price 15\% higher than } \\
\text { market price }\end{array}$ & $\begin{array}{l}\text { Price 45\% higher } \\
\text { than market price }\end{array}$ \\
\hline Which option you like? & & & \\
\hline
\end{tabular}




\section{Robustness of CBC design}

The levels within first attributes have Standard Error (SE) of 0.026, whereas the second attribute had SE of 0.021 and third attribute had SE of 0.032. Higher SE for attribute with higher number of levels is observed since each level appears fewer times in the design when the number of levels increases. SE of none of the main effects were larger than 0.05. In CBC design, SE of less than 0.05 is accepted for main effects as thumb rule for the robustness of the design, minimum sample sizes and minimum acceptable precision (Orme, 2005). This design with 180 respondents with 10 version and 12 tasks from each version meet the higher standard for this particular attribute list and set of effects.

The final analysis was carried out using the latent class model as often done in market segmentation studies. In the latent class model, the consumers were classified to different segments by the model based on the similarity and differences regarding their response to the product attributes and their levels. The Consistent Akaike Info Criterion (CAIC) criteria identified two group models as the best fitted model, but the numbers of segments were too low for drawing out meaningful conclusion. Therefore, the model with three segments, which has next lowest CAIC, were selected for the interpretation in all sites. The latent class model of three groups grouped the consumers in three distinct segments according to preferences of consumers which was useful to make meaningful interpretation for consumer segmentation. The sign of 'Part Worth Utility (PWU)' values were read as the consumer preference where the positive (+) PWU indicating 'like' and negative (-) PWU indicating 'dislike' to the attribute level. The statistical significance of the PWU were analysed for $\mathrm{P}=0.01$ and $\mathrm{P}=0.05$ whereas $\mathrm{PWU}$ not significant at $95 \%$ confidence level were considered non-significant preference or indifference.

For objective 2, consumers' WTP for switching from conventional to pesticide-free, traditional, and organic farming products were quantified by using the equation 1 in MS Excel spread sheet. This was calculated by using the method described by Orme (2001). The formula for calculation of WTP for switching from one level to other level was as follows:

$$
C S=-\frac{1}{\beta m}\left(V^{\prime}-V\right) ;
$$

\section{RESULTS AND DISCUSSIONS}

Consumers' preference for different attributes of pesticide-safe vegetables for different segments

Different consumer segments had clear and distinct characteristics regarding their preference and importance for different attributes of the vegetables. Figure 1 shows the relative importance of the different attributes for different consumer segments separated by the four markets.

For the largest consumer segment in Kathmandu market, production method was the most important attribute carrying about $40 \%$ weight followed by price $(32.8 \%$ weight) and labelling (27.2\% weight) (Figure 1). For the second segment, however, the price was the most important attribute $(55.1 \%$ weight $)$ whereas production method was second important $(30.4 \%$ weight $)$ and price was the least important attribute (14.6\% weight). For the third consumer segment, production method carried even higher importance $(71.0 \%$ weight); price was second important attribute carrying $21.3 \%$ weight whereas this group gave very little importance $(7.7 \%$ weight) on the labelling.

In Pokhara market, for the largest consumer segment, price was the most important attribute carrying about $64.1 \%$ weight followed by production method and labelling. For the second segment, the price was the most important attribute $(42.5 \%$ weight) whereas production method was second important $(38.1 \%$ weight) and labelling was the least important attribute $(19.4 \%$ weight). For the third consumer segment, production method carried even higher importance (50.3\% weight), price was second important attribute carrying $25.6 \%$ weight whereas this group gave very little importance $(24.1 \%$ weight) on the price.

For the largest consumer segment of Chitwan market, price was the most important attribute carrying about $53.5 \%$ weight followed by production method and labelling. For the second segment, the production method was the most important attribute $(51.7 \%$ weight $)$ whereas price was second important $(25.6 \%$ weight $)$ and labelling was the least important attribute $(22.7 \%$ weight). For the third consumer segment, production method carried even higher importance (61.2\% weight), price was second important attribute carrying $21.9 \%$ weight whereas this group gave very little importance ( $17.0 \%$ weight) on the price.

where: CS is willingness to pay, $\beta m$ is parameter estimate for price, $V^{\prime}$ is the utility of desired level and $V$ is utility of initial level 


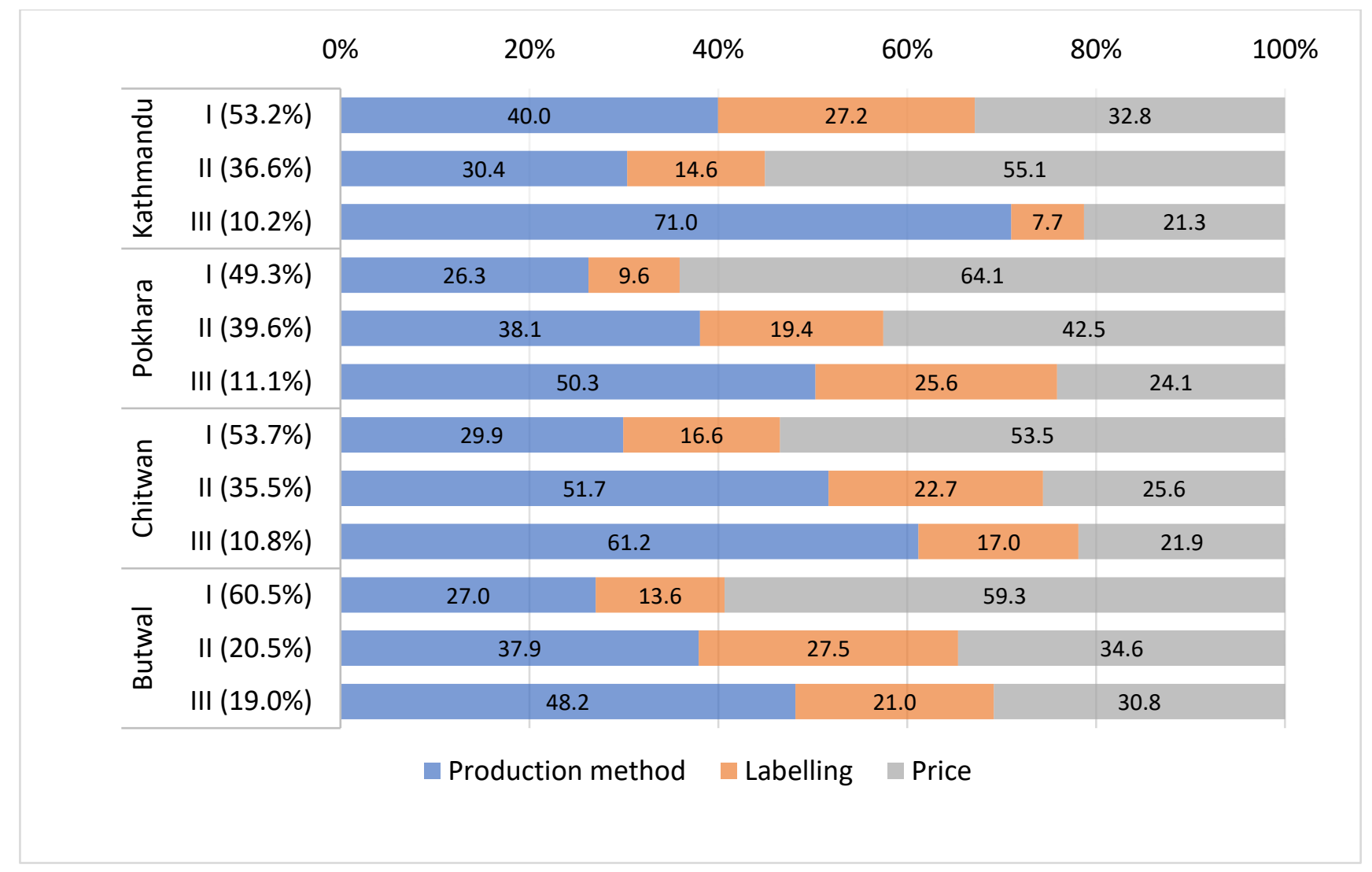

Figure 1: Relative importance of attributes by consumer segments by markets (importance are in percentage) (source: consumer survey)

Largest consumer segment of Butwal market, price was the most important attribute carrying about $59.3 \%$ weight followed by production method and labelling. For the second segment, the production method was the most important attribute $(37.9 \%$ weight) whereas price was second important (34.6\% weight) and labelling was the least important attribute (27.5\% weight). For the third consumer segment, production method carried even higher importance (48.2\% weight), price was second important attribute carrying $30.8 \%$ weight, whereas this group gave very little importance ( $21.0 \%$ weight) on the labelling.

Thus, price was the most prioritized attribute for majority of consumers in Pokhara (78.9\%), Chitwan (53.7\%) and Butwal $(60.5 \%)$ and sizable $36.6 \%$ of consumers in Kathmandu. There are dearth of studies relating premium price to traditional or pesticide-free production in Nepal however in case of organic products, 'high price' has been always reported as one critical constraint for promoting organic vegetables (Bhatta et al., 2009; Bardhan et al., 2019; Sharma et al., 2016). This suggests that there is need for producing safe food without much expected premium price. This is possible by promoting safer mid-way alternatives to vegetable grown under pesticide-laden conventional system as well as expensive organic system.
One strategy could be promoting products from traditional system which covers $96 \%, 80 \%$ and $41 \%$ agriculture lands in Mountain, Hill and Terai region of Nepal, respectively, which produces pesticide-safe food but are marketed as conventional products (PDD, 2014; Gurung et al., 2016; Palikhey et al., 2017). Another strategy could be promoting pesticide-free products allowing supplemental application of production limiting soil nutrients. Lower crop yield under organic system has also been reported in Nepal (Dahal and Dhakal, 2016; Singh et al., 2015). Deficiency of nitrogen is one of the main factors limiting productivity under organic farming (Askegaard et al., 2011). Therefore, allowing supplemental nitrogen fertilizer but restricting pesticide can be mid-way compromise to produce affordable and pesticide-safe vegetables. This study also verified that consumers are willing to pay some premium price for these mid-way alternatives to organic products. Production method was the most important attribute for $63.4 \%$ consumers in Kathmandu, $50.7 \%$ consumers in Pokhara, $46.3 \%$ consumers in Chitwan and $39.5 \%$ consumers in Butwal, indicating there is still potential of premium price for products grown under those production methods. Consumers in Kathmandu were found to be prioritizing production method over price possibly due to relatively higher income and greater awareness 
about pesticide-safety issues in Kathmandu. Adhikari et al. (2012) also reported educated and economically better consumers in Kathmandu preferred product quality over price.

\section{Consumers' preference for different levels of attributes}

The consumer segments identified by the selected threegroup latent class models are presented in Table 2. Firstly, the result showed significantly negative preference to price attribute in all markets and all consumer segments, which indicated confirmation to the negatively sloped demand curve/law of demand, thereby indicating robust construct validity of the models. Similarly, almost all consumer segments in all markets had significantly positive preference for products with label which is understandable as labels provide the information and assurance about product quality. These findings are aligned to previous findings suggesting consumers were willing to pay higher for products with organic certification and labelling in Nepal (Kattel et al., 2020; Bhattarai, 2019; Aryal et al., 2009) and globally (Padilla et al., 2007; McCluskey \& Loureiro, 2003).

The results showed that in Kathmandu, all three segments of the consumers had significantly negative preference for vegetables grown under conventional system (applying both chemical fertilizers and pesticides). The largest consumer segment in Kathmandu constituted $53.2 \%$ consumers and it was characterised by significant positive preference for pesticide-free, traditional, and organic products. These consumers had positive preference for labelled products. The second segment constituted $36.6 \%$ consumer who were also similar to first segment except that these consumers were indifferent to pesticide-free products unlike the first segment who were positive toward pesticide-free. The third segment, which constituted a small $10.2 \%$ consumers, but had unique preference. These consumers had positive preference toward organic products while being in different to any other alternatives.

All consumer segments in Pokhara had significant negative preference for vegetables coming from conventional system. Differences were observed in preferences regarding the production methods. The largest consumer segment (49.3\%) in Pokhara had significantly positive preference for organic products. This segment was indifferent to pesticide-free products but had significant positive preference to traditional products. The second largest segment in Pokhara constituted 39.6\% consumers, who had significant negative preference for pesticide-safe products but had positive preference to traditional and organic products. The third segment of consumer constituted $11.1 \%$ of people, who had positive preference for products grown under pesticide-free methods, traditional methods and organic methods.

Like in earlier markets, all three consumer segments in Chitwan had significant negative preference for the vegetables produced under conventional system. All segments had significant positive preference to vegetables grown under traditional and organic systems as well as products with labels. The difference in the preference was observed in preference toward pesticide-free production methods. The largest consumer segment in Chitwan with $53.7 \%$ of the consumers in the segment were indifferent to pesticide-free products. The second segment was composed of $35.5 \%$ consumers who had strong positive preference for pesticide-free products. The third segment constituted $10.8 \%$ of consumers, who had significant negative preference to pesticide-free production methods.

In Butwal market, all consumer segments had significantly negative preference to vegetables produced under conventional system applying both pesticide and fertilizers. The difference of consumer preference was once again due to differential preference for production methods. In Butwal market, all consumer segments had strong significant positive preference to traditional and organic products. However, the largest consumer segment in Butwal, which constituted $60.5 \%$ of consumer, were indifferent to the products grown under pesticide-free methods. The second segment constituting $20.5 \%$ of consumers had significant positive preference to pesticidefree products. The third segment composed of $19.0 \%$ of the consumers had negative preference for products grown pesticide-free products.

The largest consumer segments in Pokhara, Chitwan and Butwal market (constituting about 49-61\% consumers) had similar characterisation - negative preference to conventional products; positive preference to vegetable grown under traditional system and organic systems; and positive preference to labelled products. There was mixed preference for pesticide-safe products as larget consumer section in Kathmandu market also had positive preference to such products whereas in other market where consumers did not had significant preference on this possibly due to this mid-way compromise not being well understood to them. The result also indicated that there was a small but sizable segment of consumers (10-19\% depending on market) who had positive preference for organic and traditional products except in Kathmandu. This consumer segment could be key for establishing speciality markets for organic and traditional products.

Products produced under conventional systems were disliked by consumers, irrespective of market, indicating an increased knowledge about the food safety issues among urban consumers in Nepal. It was evident that 
majority of the consumers preferred safer production alternatives - either pesticide-free or traditional or organic products which showed a great scope for promotion of these products. Despite such strong consumer preference toward pesticide-free, traditional and organic products, the lack of sizable market transection of vegetables grown under these systems is a contradiction. This contradiction is mainly due to mismatch between consumer's WTP and affordability. Consumers who dislike conventional products may still consume those products due to several individual factors like value and risk taking attributes as well as external constraints like unavailability of alterative product, high transection cost, low quality assurance and low affordability (Eide and Toft, 2013; Tandon et al., 2021; Singh and Verma, 2017).

Another striking finding across most of the market that there were sizable numbers $(53.2 \%$ in Kathmandu, $11.1 \%$ in Pokhara, $35.5 \%$ in Chitwan, $20.5 \%$ in Butwal) of consumers who preferred organic products also preferring pesticide-free products indicating consumers were more worried about pesticide toxicity than fertilizer. This suggested toward the possibility of promoting pesticidesafe production methods without falling in potential production hiccup for converting to organic. For all alternative production methods, labelling was important. Therefore, innovative certification and labelling without adding much to the cost, such as participatory guarantee systems (PGS) or geographical labelling, would be useful for meeting labelling requirements.

\section{Consumers' WTP to switch from inferior to superior levels of each attributes}

Table 3 shows maximum percentage of additional price consumers were willing to pay for switching to greater level of food-safety categories from poor level of food safety category. Since most of the current consumers were consuming vegetables with both pesticide and fertilizer residue or produce without label, no reverse switching was relevant for this study.

The analysis of WTP showed that the largest consumer segment in Kathmandu (53.2\%) had willing to pay $41.8 \%$ for pesticide-free products, $47.3 \%$ higher for traditional products and $54.7 \%$ higher for complete organic products. Those consumers were also willing to pay $37.2 \%$ higher for labelled products compared to non-labelled products. About $36.6 \%$ consumers in Kathmandu were willing to pay additional $14.3 \%, 17.0 \%$ and $24.8 \%$ for pesticide-free, traditional and organic products, respectively, and $11.9 \%$ higher for labelled products. Remaining $10.2 \%$ consumers were willing to pay $51.2 \%$ higher to organic products compared to conventional products and $16.4 \%$ higher to labelled product compared to non-labelled products. In
Pokhara, the largest consumer segment (49.30\%) had WTP $10.4 \%$ higher for pesticide-free, $12.1 \%$ higher for traditional and $18.5 \%$ higher for organic products. Those consumers were also willing to pay $6.8 \%$ higher for labelled products. Similarly, $39.6 \%$ consumers from second segment were willing to pay $20.6 \%, 31.6 \%$ and $40.2 \%$ higher for pesticide-free, traditional and organic products, respectively. Remaining $11.10 \%$ consumers were willing to pay $75.8 \%, 83.2 \%$ and $93.5 \%$ higher for pesticide-free, traditional and organic products, respectively. Further, the results indicated that the largest consumer segment in Chitwan (53.70\%) had WTP $15.5 \%$ higher for pesticide-free products, $20.6 \%$ higher for traditional and $25.3 \%$ for organic vegetables. Those consumers were also willing to pay $14 \%$ higher for labelled products. The second largest segment (composed of $35.50 \%$ consumers) was willing to pay $75.7 \%, 79.6 \%$ and $90.8 \%$ higher for pesticide-free, traditional and organic produce, respectively. Remaining $10.80 \%$ consumers from third segment in Chitwan were willing to pay $40 \%$, $105.9 \%$ and $125.3 \%$ higher for pesticide-free, traditional and organic products, respectively. The largest consumer segment in Butwal $(60.50 \%)$ was willing to pay $11.7 \%$ higher for pesticide-free products, $14.9 \%$ higher for traditional products and $20.5 \%$ for organic products. Those consumers were also willing to pay $10.3 \%$ higher for labelled products compared to non-labelled products. Other $20.50 \%$ consumers in Butwal were willing to pay $35.5 \%, 45.8 \%$ and $49.2 \%$ higher for pesticide-free, traditional and organic products whereas remaining $19.0 \%$ consumers from third segment were willing to pay $31.8 \%$, $50.6 \%$ and $69.8 \%$ higher for pesticide-free, traditional and organic products, respectively.

It is apparent that sizable proportion of consumers were willing to pay premium price to shift from low food-safety levels to higher food-safety levels in all markets. It is understandable that consumers want to switch to higher quality of food. Few previous findings have also suggested that urban consumers were willing to pay premium price for safe food, particularly in context of organic food. For instance, Bhattarai (2019) reported that WTP on an average of $25 \%$ higher for organic products. Atreya et al. (2012) reported that individuals were willing to pay 53$79 \%$ more than the existing pesticide price to protect their health and environment. Similarly, Rai and Adhikari (2016) reported that consumers are willing to pay up to $31 \%$ additional prices for organic vegetables. Aryal et al. (2009) found that $58 \%$ of the consumers in Nepal were willing to pay $6-20 \%$ price premium, whereas $13 \%$ consumers were willing to pay up to $50 \%$ premium. This study also confirmed the findings from like Balogh et al. (2016) who reported that traditional food products can 
command a substantial premium price if effective quality certification and authentic product composition is maintained. There is no previous study about consumer WTP for pesticide-free products in Nepal, but the findings are aligned with studies indicating positive WTP price premium for pesticide-free products (Khan et al., 2018; Hayati et al., 2017) or pesticide-safe products (Cobbinah et al., 2018; Vidogbéna et al., 2015).

Despite that, caution is warranted in interpreting these results. It is likely that consumers who expressed strong WTP to organic, pesticide-free, or traditional products in hypothetical market may not actually pay premium price in real market. Using a meta-analysis of 80 worldwide studies, Li and Kallas (2021) suggested that WTP estimate derived from hypothetical market scenario like choice experiment was higher than real transection analysis due to hypothetical bias. Regardless of this, the result indicates toward strong potential for specialty market and opportunity to promote safer mid-way alternative production methods.

\section{CONCLUSION AND RECOMMENDATION}

Different typologies of safe-food production systems are available in the continuum between conventional, traditional, green-revolution paradigm and pure organic system which may produce pesticide-safe food in affordable price. Among them, traditional production system which is by-default organic but lacks certification, and pesticide-free system where pesticides are not allowed but synthetic fertilizer is allowed, can be mid-way safer compromise for poor, food insecure countries, such as Nepal. However, these alternatives are seldom recognized and made authentically available to consumers. This study explored consumers' perceptions about these mid-way alternatives along with organic system and found that sizable segment of consumers has positive preference to these alternatives. Our study also validated that consumers are willing to pay highest premium price to pure organic products; however, there are large groups of consumers who do not prefer to pay high premium price for pure organic products. Thus, it seems that there is strong market demand for pesticide-free and traditional products which need to be harnessed for improving agriculture marketing as well as food-safety agenda in Nepal. Alternative certification and labelling practices which would not put high price hike for safe-food like organic certification does could be optimal solution to develop speciality market and realize the price premium for products coming from relatively safer food production systems. These alternative production systems need to be streamlined in policy about agriculture marketing and food-safety to supply safer food for consumers.

Table 2: Part Worth Utility of consumer preference by market and consumer segments (source: consumer survey)

\begin{tabular}{|c|c|c|c|c|c|c|c|c|c|c|c|c|}
\hline & Kathma & & & Pokhara & & & Chitwan & & & Butwal & & \\
\hline segments & Seg1 & Seg2 & Seg3 & Seg1 & Seg2 & Seg3 & Seg1 & Seg2 & Seg3 & Seg1 & Seg2 & Seg3 \\
\hline $\begin{array}{l}\text { Consumer } \\
\text { segment size }\end{array}$ & $53.2 \%$ & $36.6 \%$ & $10.2 \%$ & $49.3 \%$ & $39.6 \%$ & $11.1 \%$ & $53.7 \%$ & $35.5 \%$ & $10.8 \%$ & $60.5 \%$ & $20.5 \%$ & $19.0 \%$ \\
\hline
\end{tabular}

Production

method

\begin{tabular}{|c|c|c|c|c|c|c|c|c|c|c|c|c|}
\hline Conventional & $-4.17^{* *}$ & $-2.85^{* *}$ & $13.14^{\mathrm{ns}}$ & $-2.53^{* *}$ & $-2.68^{* *}$ & $-8.27^{* *}$ & $-2.55^{* *}$ & $-7.75^{* *}$ & $-5.15^{* *}$ & $-2.24^{* *}$ & $-5.74^{* *}$ & $-2.70^{* *}$ \\
\hline $\begin{array}{l}\text { Pesticide- } \\
\text { free }\end{array}$ & $0.68^{* *}$ & $0.21^{\mathrm{ns}}$ & $1.26^{\mathrm{ns}}$ & $0.17^{\mathrm{ns}}$ & $-0.29^{* *}$ & $1.66^{*}$ & $0.13^{\mathrm{ns}}$ & $1.79^{* *}$ & $-2.12^{* *}$ & $-0.04^{\mathrm{ns}}$ & $0.50^{* *}$ & $-0.44^{* *}$ \\
\hline Traditional & $1.31^{* *}$ & $0.54^{* *}$ & $5.11^{\mathrm{ns}}$ & $0.40^{*}$ & $0.99^{* *}$ & $2.63^{* *}$ & $0.83^{* *}$ & $2.28^{* *}$ & $2.90^{* * *}$ & $0.60^{* *}$ & $2.32^{* *}$ & $0.89^{* *}$ \\
\hline Organic & $2.17^{* *}$ & $2.10^{* *}$ & $6.76^{*}$ & $1.96^{* *}$ & $1.98^{* *}$ & $3.98^{* *}$ & $1.60^{* *}$ & $3.69^{* *}$ & $4.37^{* *}$ & $1.67^{* *}$ & $2.92^{* *}$ & $2.25^{* *}$ \\
\hline without label & $-2.16^{* *}$ & $-1.19^{* *}$ & $-1.08^{* *}$ & $-0.82^{* *}$ & $-1.19^{* *}$ & $-3.11^{* *}$ & $-1.15^{* *}$ & $-2.51^{* *}$ & $-1.32^{* *}$ & $-0.99^{\text {** }}$ & $-3.14^{* *}$ & $-1.08^{* *}$ \\
\hline with label & $2.16^{* *}$ & $1.19^{* *}$ & $1.08^{* *}$ & $0.82^{* *}$ & $1.19^{* *}$ & $3.11^{* *}$ & $1.15^{* *}$ & $2.51^{* *}$ & $1.32^{* *}$ & $0.99^{* *}$ & $3.14^{* *}$ & $1.08^{* * *}$ \\
\hline
\end{tabular}

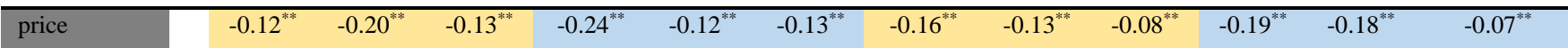

Note: $* *$ and $*$ indicate the significant at $\mathrm{P}=0.01$ and $\mathrm{P}=0.05$ respectively, ${ }^{\text {ns }}$ indicate value not significant at $95 \%$ confidence level 
Table 3: Consumers' Willingness to Pay to switch from lower food-safety attributes to higher food-safety categories (source: consumer survey)

\begin{tabular}{|c|c|c|c|c|c|c|c|c|c|c|c|c|c|}
\hline \multicolumn{2}{|c|}{ Switching } & \multicolumn{3}{|c|}{ Kathmandu } & \multicolumn{3}{|c|}{ Pokhara } & \multicolumn{3}{|c|}{ Chitwan } & \multicolumn{3}{|c|}{ Butwal } \\
\hline From & To & $\begin{array}{c}\text { Seg } 1 \\
(53.2 \\
\%)\end{array}$ & $\begin{array}{c}\text { Seg } 2 \\
(36.6 \\
\%)\end{array}$ & $\begin{array}{c}\text { Seg } 3 \\
(10.2 \\
\%)\end{array}$ & $\begin{array}{c}\text { Seg } 1 \\
(49.3 \\
\%)\end{array}$ & $\begin{array}{c}\text { Seg } 2 \\
(39.6 \\
\%)\end{array}$ & $\begin{array}{c}\text { Seg } 3 \\
(11.1 \\
\%)\end{array}$ & $\begin{array}{c}\text { Seg } 1 \\
(53.7 \\
\%)\end{array}$ & $\begin{array}{c}\text { Seg } 2 \\
(35.5 \\
\%)\end{array}$ & $\begin{array}{c}\text { Seg } 3 \\
(10.8 \\
\%)\end{array}$ & $\begin{array}{c}\text { Seg } 1 \\
(60.5 \\
\%)\end{array}$ & $\begin{array}{c}\text { Seg } 2 \\
(20.5 \\
\%)\end{array}$ & $\begin{array}{c}\text { Seg } 3 \\
(19.0 \\
\%)\end{array}$ \\
\hline \multirow{3}{*}{$\begin{array}{l}\text { Conventio } \\
\text { nal }\end{array}$} & $\begin{array}{l}\text { Pesticide } \\
\text {-free }\end{array}$ & 41.8 & 14.3 & NR & 10.4 & 20.6 & 75.8 & 15.5 & 75.7 & 40.0 & 11.7 & 35.5 & 31.8 \\
\hline & $\begin{array}{l}\text { Traditio } \\
\text { nal }\end{array}$ & 47.3 & 17.0 & NR & 12.1 & 31.6 & 83.2 & 20.6 & 79.6 & 105.9 & 14.9 & 45.8 & 50.6 \\
\hline & Organic & 54.7 & 24.8 & 51.2 & 18.5 & 40.2 & 93.5 & 25.3 & 90.8 & 125.3 & 20.5 & 49.2 & 69.8 \\
\hline \multirow{2}{*}{$\begin{array}{l}\text { Pesticide- } \\
\text { free }\end{array}$} & $\begin{array}{l}\text { Traditio } \\
\text { nal }\end{array}$ & 5.4 & 2.7 & NR & 1.6 & 11.1 & 7.4 & 5.0 & 3.9 & 66.0 & 3.2 & 10.3 & 18.8 \\
\hline & Organic & 12.8 & 10.5 & 51.2 & 8.1 & 19.6 & 17.7 & 9.7 & 15.1 & 85.4 & 8.8 & 13.8 & 38.0 \\
\hline $\begin{array}{l}\text { Traditiona } \\
1\end{array}$ & Organic & 7.4 & 7.8 & 51.2 & 6.4 & 8.5 & 10.3 & 4.7 & 11.2 & 19.4 & 5.6 & 3.4 & 19.2 \\
\hline $\begin{array}{l}\text { Without } \\
\text { label }\end{array}$ & $\begin{array}{l}\text { With } \\
\text { label }\end{array}$ & 37.2 & 11.9 & 16.4 & 6.8 & 20.5 & 47.5 & 14.0 & 39.9 & 34.8 & 10.3 & 35.7 & 30.5 \\
\hline
\end{tabular}

\section{ACKNOLEDGEMENTS}

I would like to acknowledge all the consumers for their response in the study. I want to thank to Samichhya Gautam, Kabita Subedi, Rabin Rijal, Shashank Kafley, Pawan Marahatta, and Bijaya Paudel for their help in data collection in the consumer survey.

\section{REFRERNCES}

[1] Adams, D. C., \& Salois, M. J. (2010). Local versus organic: A turn in consumer preferences and willingness-to-pay. Renewable agriculture and food systems, pp. 331-341.

[2] Adhikari, R. P., Collins, R., \& Sun, X. (2012). Segmenting consumers to inform agrifood value chain development in Nepal. International Food and Agribusiness Management Review, 15(4), 93-114.

[3] Aryal, K. P., Chaudhary, P., Pandit, S., \& Sharma, G. (2009). Consumers' willingness to pay for organic products: a case from Kathmandu valley. Journal of Agriculture and Environment, 10: 15-26.

[4] Askegaard, M., Olesen, J. E., Rasmussen, I. A., \& Kristensen, K. (2011). Nitrate leaching from organic arable crop rotations is mostly determined by autumn field management. Agriculture, ecosystems \& environment, 142(3-4): 149-160.

[5] Aswathy, M. V. D., \& Thomas, S. (2019). Demand, acceptability and e-marketing of organic products. International Journal of Management and Social Sciences (IJMSS), 8(2.1), 28-31.

[6] Atreya, K., Johnsen, F. H., \& Sitaula, B. K. (2012). Health and environmental costs of pesticide use in vegetable farming in Nepal. Environment, Development and Sustainability, 14(4), 477-493.
[7] Balogh, P., Békési, D., Gorton, M., Popp, J., \& Lengyel, P. (2016). Consumer willingness to pay for traditional food products. Food policy, 61, 176-184.

[8] Bardhan, T., Singh, S. P., Paul, S., Sangeetha, V., Bhowmik, A., \& Venkatesh, P. (2019). Constraints in the consumption of organic foods in Eastern India. Indian Journal of Extension Education, 55(3), 102-106.

[9] Becker, N. (2017). External costs of food production: environmental and human health costs of pest management. Environmental pest management: challenges for agronomists, ecologists, economists and policy makers, 369.

[10] Becker, N., Tavor, T., Friedler, L., \& Bar, P. (2015). Two stages decision process toward organic food: The case of organic tomatoes in Israel. Agroecology and Sustainable Food Systems, 39(3), 342-361.

[11] Bhatta, G. D., \& Doppler, W. (2011). Smallholder periurban organic farming in Nepal: A comparative analysis of farming systems. Journal of Agriculture, Food Systems, and Community Development, 1(3), 163-180.

[12] Bhatta, G. D., Doppler, W., \& KC, K. B. (2009). Potentials of organic agriculture in Nepal. Journal of Agriculture and Environment, 10, 1-14.

[13] Bhatta, G. D., Doppler, W., \& KC, K. B. (2010). Urban demands for organic tomatoes in the Kathmandu Valley, Nepal. Middle East Journal of Scientific Research,5(4), 199-209.

[14] Bhattarai, K. (2019). Consumers' willingness to pay for organic vegetables: Empirical evidence from Nepal. Economics \& Sociology, 12(3), 132-146.

[15] Cobbinah, M. T., Donkoh, S. A., \& Ansah, I. G. K. (2018). Consumers' willingness to pay for safer vegetables in Tamale, Ghana. African Journal of Science, Technology, Innovation and Development, 10(7), 823-834. 
[16] Dahal, K. R., \& Dhakal, S. C. (2016). The relative efficiency of organic farming in Nepal. Published by the South Asian Network for Development and Environmental Economics (SANDEE), PO Box, 8975.

[17] Edenbrandt, A. K. (2018). Demand for pesticide-free, cisgenic food? Exploring differences between consumers of organic and conventional food. British Food Journal.

[18] Eide, B., \& Toft, M. (2013). Consumer behavior theoriesPurchasing organic food. Bachelor Thesis, Aarhus University, Aarhus, Denmark.

[19] FAOSTAT, 2021. http://www.fao.org/faostat/en/\#data.

[20] Gauchan, D., Palikhey, E., Sthapit, S., Joshi, B. K., Manandhar, H. K., \& Jarvis, D. I. (2020). Organic farming and marketing of traditional crops in Nepal Mountains: Gaps, issues and opportunities for improvement. Traditional Crop Biodiversity for Mountain Food and Nutrition Security in Nepal, 163.

[21] Hayati, B., Haghjou, M., \& Peshbahar, E. (2017). Effecting factors on consumers' willingness to pay a premium for pesticide-free fruit and vegetables in Iran. MOJ Food Processing \& Technology, 4(5).

[22] Kattel, R. R., Regmi, P. P., Sharma, M. D., \& Thapa, Y. B. (2020). Consumers' preference and willingness to pay for Nepalese large cardamom in the Global Market. International Journal of Social Sciences and Management, 7(2), 55-69.

[23] Khan, J., Khanal, A. R., Lim, K. H., Jan, A. U., \& Shah, S. A. (2018). Willingness to pay for pesticide free fruits: Evidence from Pakistan. Journal of International Food \& Agribusiness Marketing, 30(4), 392-408.

[24] Khanal, S. (2020). Consumers' willingness, behaviors, and attitudes to pay a price premium for local organic foods in Nepal. International Journal of Environment, Agriculture and Biotechnology, 5(3), 594-609.

[25] Li, S., \& Kallas, Z. (2021). Meta-analysis of consumers' willingness to pay for sustainable food products. Appetite, 105239.

[26] McCluskey, J. J., \& Loureiro, M. L. (2003). Consumer preferences and willingness to pay for food labeling: a discussion of empirical studies. Journal of Food Distribution Research, 34(856-2016-57150), 95-102.

[27] Miškolci, S. (2014). Consumer preferences and willingness to pay for the health aspects of food. Acta Universitatis Agriculturae et Silviculturae Mendelianae Brunensis, 59(4), 167-176.

[28] Ndlovu, N., Mafumbate, J., Mafuka, A., \& Brena, M. (2016). The impact of the Buy Zimbabwe Campaign on performance of Zimbabwean companies in the retail sector. Journal of Economics and Behavioral Studies, 8(6), 227-236.

[29] Orme, B. K. (2001). Assessing the monetary value of attribute levels with conjoint analysis: Warnings and suggestions. Sawtooth Solutions Customer Newsletter (Spring) Sawtooth Software Inc., Sequim, WA.

[30] Orme, B. K. (2005). Getting started with conjoint analysis: strategies for product design and pricing research. Research Publishers.
[31] Padilla, C., Villalobos, P., Spiller, A., \& Henry, G. (2007). Consumer preference and willingness to pay for an officially certified quality label: Implications for traditional food producers. Agricultura tecnica, 67(3), 300-308.

[32] Palikhey, E., Sthapit, S. R., Gautam, S., Gauchan, D., Bhandari, B., Joshi, B. K., \& Sthapit, B. R. (2017). Baseline Survey Report: Hanku, Jumla. Integrating traditional crop genetic diversity into technology: Using a biodiversity portfolio approach to buffer against unpredictable environmental change in the Nepal Himalayas. Pokhara, Nepal: LI-BIRD, NARC and Bioversity International.

[33] Posri, W., Shankar, B., \& Chadbunchachai, S. (2006). Consumer attitudes towards and willingness to pay for pesticide residue limit compliant "safe" vegetables in Northeast Thailand. Journal of International Food \& Agribusiness Marketing, 19(1), 81-101.

[34] PPD, 2014. National pesticide consumption statistics in Nepal. Plant Protection Directorate (PDD), Department of Agriculture, Nepal.

[35] PQPMC, 2019. Annual program and statistics book 2018/019. Plant Quarantine and Pesticide Management Center, Nepal.

[36] Raghavarao, D., Wiley, J. B., \& Chitturi, P. (2010). Choicebased conjoint analysis: models and designs. CRC Press.

[37] Rai, K., \& Adhikari, R. K. (2016). Organic agriculture: willingness to pay for organic vegetables in Kathmandu valley. Nepalese Journal of Agricultural Sciences, 14, 4349.

[38] Sharma, P., Uprety, P., \& Phuyal, R. K. (2016). An Analysis of consumer's purchase behavior on organic foods in Kathmandu valley. Advances in Economics and Business Management (AEBM), 3(5), 514-526.

[39] Singh, A., \& Verma, P. (2017). Factors influencing Indian consumers' actual buying behaviour towards organic food products. Journal of cleaner production, 167, 473-483.

[40] Singh, M., \& Maharjan, K. L. (2015). The market for local organic produce in urban and semi-urban areas of Nepal: A case study of Kathmandu valley and Chitwan district. Journal of Contemporary India Studies: Space and Society, 5, 39-49.

[41] Singh, M., Maharjan, K. L., \& Maskey, B. (2015). Factors influencing organic farm income in Chitwan district of Nepal (No. 1008-2016-80158).

[42] Singh, R., \& Singh, G. S. (2017). Traditional agriculture: a climate-smart approach for sustainable food production. Energy, Ecology and Environment, 2(5), 296316.

[43] Tandon, A., Jabeen, F., Talwar, S., Sakashita, M., \& Dhir, A. (2021). Facilitators and inhibitors of organic food buying behavior. Food Quality and Preference, 88, 104077.

[44] Vidogbéna, F., Adégbidi, A., Tossou, R., Assogba-Komlan, F., Martin, T., Ngouajio, M., ...\& Zander, K. K. (2015). Consumers' willingness to pay for cabbage with minimized pesticide residues in Southern Benin. Environments, 2(4), 449-470. 